\title{
Prevalence and associated factors of intimate partner violence amongst women attending prevention of mother to child transmission services in Blantyre, Malawi
}

\begin{tabular}{|c|c|}
\hline \multicolumn{2}{|c|}{$\begin{array}{l}\text { Authors: } \\
\text { Lignet Chepuka }^{1} \\
\text { Chimwemwe Kwanjo-Banda }^{1} \\
\text { Ursula Kafulafula }^{2} \\
\text { Anthony Sefasi }^{3} \text { (D) } \\
\text { Genesis Chorwe-Sungani }^{3} \text { (D) }\end{array}$} \\
\hline \multicolumn{2}{|c|}{$\begin{array}{l}\text { Affiliations: } \\
{ }^{1} \text { Department of Adult Health, } \\
\text { Faculty of Nursing Health } \\
\text { Studies, Kamuzu College of } \\
\text { Nursing, University of } \\
\text { Malawi, Blantyre, Malawi }\end{array}$} \\
\hline \multicolumn{2}{|c|}{$\begin{array}{l}\text { 2Department of Midwifery, } \\
\text { Faculty of Midwifery Studies, } \\
\text { Kamuzu College of Nursing, } \\
\text { University of Malawi, } \\
\text { Blantyre, Malawi }\end{array}$} \\
\hline \multicolumn{2}{|c|}{$\begin{array}{l}{ }^{3} \text { Department of Mental } \\
\text { Health, Faculty of Community } \\
\text { Health Studies, Kamuzu } \\
\text { College of Nursing, University } \\
\text { of Malawi, Blantyre, Malawi }\end{array}$} \\
\hline \multicolumn{2}{|c|}{$\begin{array}{l}\text { Corresponding author: } \\
\text { Genesis Chorwe-Sungani, } \\
\text { genesischorwe@kcn.unima. } \\
\text { mw }\end{array}$} \\
\hline \multicolumn{2}{|c|}{$\begin{array}{l}\text { Received: } 31 \text { Dec. } 2020 \\
\text { Accepted: } 12 \text { Mar. } 2021 \\
\text { Published: } 07 \text { Oct. } 2021\end{array}$} \\
\hline \multicolumn{2}{|c|}{$\begin{array}{l}\text { How to cite this article: } \\
\text { Chepuka L, Kwanjo-Banda C, } \\
\text { Kafulafula U, Sefasi A, } \\
\text { Chorwe-Sungani G. Prevalence } \\
\text { and associated factors of } \\
\text { intimate partner violence } \\
\text { amongst women attending } \\
\text { prevention of mother to child } \\
\text { transmission services in } \\
\text { Blantyre, Malawi. S Afr Fam } \\
\text { Pract. 2021;63(1), a5271. } \\
\text { https://doi.org/10.4102/safp. } \\
\text { v63i1.5271 }\end{array}$} \\
\hline \multicolumn{2}{|l|}{ Read online: } \\
\hline 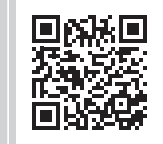 & $\begin{array}{l}\text { Scan this QR } \\
\text { code with your } \\
\text { smart phone or } \\
\text { mobile device } \\
\text { to read online. }\end{array}$ \\
\hline
\end{tabular}

Background: Intimate partner violence (IPV) during the perinatal period and when one is HIV-positive is a great concern because of the physical and mental impacts it has on health and on adherence to prevention of mother to child transmission (PMTCT) services. However, factors associated with IPV amongst perinatal women on PMTCT services are not adequately explored in Malawi. The aim of this study was to estimate the various types of IPV and the associated factors amongst HIV-positive pregnant and postnatal women in selected health centres in Blantyre district.

Methods: In this cross-sectional study, we recruited 200 HIV-positive women from antenatal, postnatal and antiretroviral therapy (ART) clinics from four selected primary care facilities of Blantyre district. Data were collected between March and May 2018.

Results: A total of $50 \%$ of the participants reported to have experienced either physical, psychological or sexual violence from their partner in the last 12 months. The multivariate logistic regression model showed that feelings about safety of the relationship and depression were the only factors that were consistently associated with IPV in the last 12 months $(p=0.001$, Pseudo $R^{2}=0.20$ ).

Conclusion: The presence of depression and safety concerns amongst our study participants calls for serious prioritisation of psychological interventions and risk assessment in the management of HIV-positive perinatal mothers who report IPV cases.

Keywords: antenatal; depression; HIV-positive mothers; Intimate partner violence (IPV); perinatal.

\section{Introduction}

Intimate partner violence (IPV) is of great concern not only from a human rights perspective but also from economic and health perspectives. ${ }^{1}$ Violence, especially from intimate partners, during pregnancy and when one is HIV-positive can lead to poor adherence to prevention of mother-to-child transmission (PMTCT) services. ${ }^{2,3,4,5,6,7,8}$ Perceived risk of existing violence may influence disclosure or partner notification by HIV-positive women. ${ }^{9}$ Intimate partner violence may be a barrier to behavioural modifications after knowing one's sero-status, including use of barrier methods and breastfeeding practices, especially where there is poor couple communication and negotiation. ${ }^{7}$ Fear and experience of violence from partners shape women's access and adherence to PMTCT, unequal gender relations and lack of support from partners are amongst other reasons women cite for dropping out of PMTCT or pre-antiretroviral therapy (ART) services. ${ }^{10,11,12,13,14}$

Estimates indicate that $90 \%-95 \%$ participation in PMTCT strategies, including effective adherence to ART, can reduce the global infant HIV incidence below 5\%.15,16,17 Although there has been high acceptability of PMTCT in Malawi, the attrition rate in PMTCT programme is highly unacceptable. Non-adherence to PMTCT programme occurs at all stages of the ante-, peri- and post-natal period ${ }^{18}$ and not all pregnant HIV-positive women receive ART treatment. ${ }^{19}$ A review of literature by United Nations International Children and Emergency Fund (UNICEF) revealed that PMTCT coverage is estimated at $65 \%$ in 21 African countries. This means that close to a third of HIVpositive women are uncovered and not all mothers on medication adhere to it. ${ }^{20}$ 
Although $95 \%$ of pregnant women attending antenatal care in Malawi were tested for HIV, only $45 \%$ of HIV-positive pregnant women and $34 \%$ of babies born to HIV-positive mothers received antiretroviral (ARV) prophylaxis. ${ }^{21}$ Tenthani and colleagues in 2014 found that $17 \%$ of all women who started ART under Option B+ initiates all pregnant or breastfeeding women on lifelong combination antiretroviral therapy (cART) regardless of their disease stage to prevent mother to child HIV transmission, were lost to follow-up 6 months after ART initiation at one of the 540 facilities that were followed from October 2011 to March 2012. The loss to follow-up was even higher (24\%) in larger facilities with electronic medical record systems (EMRS). Women who started ART to prevent mother-to-child transmission (MTCT) during pregnancy were five times more likely never to return to the clinic after they initiated ART compared with those who started ART for their own health. ${ }^{22}$ Those who initiated ART whilst breastfeeding were twice as likely to not to return compared with those who started for their own health. ${ }^{22}$ The situation was similar for those who were initiated on ART on the day of testing. The risk of loss to follow-up was highest in facilities with large proportion of Option B+ patients..$^{22}$

The effect of IPV on uptake and adherence to PMTCT services should not be undermined, especially in the case of Malawi, where IPV is highly prevalent ranging from $23 \%$ to $59 \%$ 23,24,25,26,27,28,29 and normalised, as it is seen as an unavoidable tool in resolving conflicts ('beating is the cure for marriage' ${ }^{27}$ with 'educational' beating seen as a sign of love. ${ }^{27}$

Globally, literature shows that between $27.4 \%$ and $55.0 \%$ of

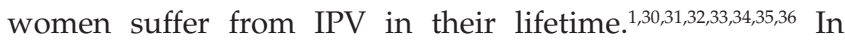
Malawi, the 2015-2016 Malawi Demographic Health Survey (MDHS) shows that $42 \%$ of women experience IPV ${ }^{1}$ although a decrease from what Chasweka and colleagues ${ }^{26}$ at Nsanje district hospital revealed (59\%) amongst women attending antenatal clinic but still much higher prevalence than many conditions routinely screened for during pregnancy. ${ }^{37}$

Intimate partner violence comes in different forms. The most commonly experienced IPV amongst women is emotional, also referred to as psychological violence. ${ }^{1,31,33}$ The other forms of IPV are physical and sexual violence. Although the prevalence of the three types of IPV amongst women in Malawi vary, the overall trend is consistent with emotional violence being the most commonly experienced $(13 \%-30 \%)$, physical $(4 \%-26 \%)$ and sexual violence $(13 \%-19 \%) .1,38$

Several factors contribute to increased risk of IPV amongst women. In a systematic review that was conducted in the United States (US), women who abused alcohol or substances were more likely to experience IPV than their counterparts. ${ }^{30}$ However, in a South African study, partner alcohol abuse was seen to pose women at risk of IPV. ${ }^{39}$ Women who experienced childhood abuse or witnessed their mothers being abused also reported IPV. ${ }^{31,39}$ Prevalence of IPV amongst women from cultures that practice male dominated relationships were higher than those from non-male dominated relationships. ${ }^{38,40}$ Studies from African settings ${ }^{31,38,39,41,42}$ including Malawi ${ }^{38,43}$ have shown that higher education has a protective factor against IPV amongst women. Furthermore, literature shows that those who enter into marriage at a tender age are likely to be abused by their intimate partners. ${ }^{41,43,44}$ However, factors associated with IPV amongst perinatal women on PMTCT services are not adequately explored in Malawi. Therefore, the aim of this study was to estimate the various types of IPV and the associated factors amongst HIV-positive pregnant and postnatal women in selected health centres in Blantyre district.

\section{Methods Study design}

In this cross-sectional study, we recruited HIV-positive women from antenatal, postnatal and ART clinics from four selected primary care facilities of Blantyre district. Two of the facilities were located in an urban setting and the other two were rural. Data were collected between March 2018 and May 2018.

\section{Sample size considerations}

An estimated 372 participants were needed to be recruited for the study. This sample size was calculated using a formula, which stipulates that: ${ }^{2,45}$

$n=Z^{2}(p)(1-p) / \mathrm{e}$,

Eqn 1

and is interpreted as follows: $n=$ sample size, $Z=$ value of a normally distributed variate, which for $95 \%$ confidence interval (CI) takes the value of 1.96 and $p=$ estimated proportion of pregnant women experiencing IPV, which is $59 \%$ (based on a previous study on IPV amongst antenatal attendees). The antenatal study was used as a proxy because we could not access a study within the country that covered the perinatal period. We added description of severe or moderate abuse: The frequency of violence was considered severe if a person reported to have experienced any form of violence more than five times and moderate if violence occurred less than five times and there were no injuries sustained requiring medical attention. Where as $e=$ desired precision or standard error, which was set at 0.05 .

\section{Inclusion and exclusion criteria}

All women who were pregnant or were within 6 weeks postnatal period were referred to the research team by nurses/ midwives or data clerks at the clinics for screening if they met the inclusion criteria. Women were recruited into the study if they were aged 18 years and above, HIV-positive and consented to participate.

\section{Data collection and instruments}

We collected data on the participants' social demographics, relationship history, HIV and IPV risk factors and attitudes and perceptions about IPV based on a literature review of factors 
associated with IPV in HIV-positive perinatal women. The interviewers administered the questionnaires. The interviewer administered questionnaire was preferred because it could be administered to participants who were illiterate and allowed the interviewers to clarify questions for the participants. This resulted in fewer unanswered items and high response rate.

The abuse assessment screen (AAS) was used to screen for IPV. ${ }^{46}$ According to a literature of IPV screening tools, there is no gold standard for IPV screening as no single IPV screening tool has well-established psychometric properties. However, the AAS was preferred because it has been found to have a high Cronbach's alpha amongst pregnant women. In a Greek study amongst pregnant women, the AAS had a Cronbach's alpha of $0.806 .{ }^{47}$ In Spain, the AAS had good test-retest reliability, specificity and construct validity amongst pregnant women. ${ }^{48}$ The self-reporting questionnaire (SRQ) was used to screen for depression. The internal consistency of the SRQ amongst Malawian women was high (Cronbach's alpha 0.825). ${ }^{49}$ The SRQ has 20 items to which participants answered yes if they experienced the symptoms or no if there were no symptoms.

\section{Data analysis}

Data were entered into a data base created in International Business Machines Corporation (IBM) Statistical Package for Social Sciences (SPSS) version 19 and exported to Stata version 14.0 for analysis. Descriptive statistics were done to calculate frequency distributions for the categorical predictor variables and severity of different types of violence experienced. The outcome variable was experience of any form of IPV in the past 12 months. Univariate logistic regression analysis was done to investigate the independent association between the outcome variable (experience of IPV) and the predictor variables (participants' social demographics, relationship history, HIV and IPV risk factors and attitudes and perceptions about IPV). Chi-square (or Fisher's exact) test were used for testing association between the binary outcome of IPV experience and the categorical predictor variables. Factors that showed association with experience of IPV at alpha 0.1 or less were included in the multivariate logistic regression model adjusting for participants age and education status as possible confounders. The results are presented in Table 5.

\section{Findings}

A total of 410 pregnant and postnatal mothers were screened for recruitment from all the four facilities. Only 207 of them met the inclusion criteria, of which 200 consented to participate in the study, giving a response rate of $96.6 \%$. Over half $(52.5 \%)$ of the participants were pregnant and $47.5 \%$ were post-natal mothers. About half (51\%) were below the age of 28 years. A total of $117(58.5 \%)$ participants attained primary school education, 178 (89\%) were Christians and 22 (11\%) were Muslims. Most of them (63.5\%) were unemployed and $57 \%$ of the participants had at least one child. Table 1 details the demographic characteristics of the 200 participants.
TABLE 1: Demographic characteristics of the participants.

\begin{tabular}{|c|c|c|}
\hline \multirow[t]{2}{*}{ Variable } & \multicolumn{2}{|c|}{ Frequency } \\
\hline & $n$ & $\%$ \\
\hline \multicolumn{3}{|l|}{ Age } \\
\hline$\leq 28$ & 102 & 51.00 \\
\hline $29>$ & 98 & 49.00 \\
\hline \multicolumn{3}{|l|}{ Level of education } \\
\hline None & 7 & 3.50 \\
\hline Primary & 117 & 58.50 \\
\hline Secondary & 71 & 35.50 \\
\hline Post-secondary & 4 & 2.00 \\
\hline Not indicated & 1 & 0.50 \\
\hline \multicolumn{3}{|l|}{ Religion } \\
\hline Christian & 178 & 89.00 \\
\hline Muslim & 22 & 11.00 \\
\hline \multicolumn{3}{|l|}{ Occupation } \\
\hline Student & 3 & 1.50 \\
\hline Unemployed & 127 & 63.50 \\
\hline Paid employees & 22 & 11.00 \\
\hline Self-employed & 48 & 24.00 \\
\hline \multicolumn{3}{|c|}{ Number of children } \\
\hline No children & 20 & 10.00 \\
\hline 1-4 children & 114 & 57.00 \\
\hline 5 and above & 66 & 33.00 \\
\hline \multicolumn{3}{|l|}{ Age of children } \\
\hline $0-18$ & 187 & 93.50 \\
\hline Above 18 & 13 & 6.50 \\
\hline \multicolumn{3}{|l|}{ Currently pregnant } \\
\hline Yes & 106 & 53.00 \\
\hline No & 94 & 47.00 \\
\hline \multicolumn{3}{|l|}{ Gestational age } \\
\hline First trimester & 14 & 13.21 \\
\hline Second trimester & 23 & 21.70 \\
\hline Third trimester & 35 & 33.02 \\
\hline Not known & 34 & 32.08 \\
\hline
\end{tabular}

A total of 189 (94.5\%) of the participants reported that they had an intimate partner. About half of them (50.5\%) had been in the relationship for less than 5 years. A total of $74.0 \%$ were in a monogamous marriage, $8 \%$ were in a polygamous marriage, $10.0 \%$ were cohabiting, $4.7 \%$ were in a stable relationship (a recognised boyfriend to the family) but not staying together and $1 \%$ were in a causal relationship (non-committal sexual relationship) whilst $1.5 \%$ were divorced. A total of 100 (50.0\%) reported that there was no tension in their relationship whilst the other $50.0 \%$ reported that there was some tension or a lot of tension in their relationship. Only $33.5 \%$ of the participants reported feeling safe in their current relationship. Over $60.0 \%$ of the partners attended secondary school education. A total of $80.0 \%$ of them were Christians and $93.5 \%$ were engaged in some form of employment. Of these, $44.0 \%$ were on paid employment. Table 2 shows the characteristics of the partners.

More than $87 \%$ of the participants did not find IPV justifiable if a woman went out without letting her husband know, failed to care for the children, answered back to her husband during an argument, refused sex or burnt food. Table 3 shows the proportion of participants who found some situations justifiable for a man to beat a woman. 
TABLE 2: Characteristics of the partners to the participants.

\begin{tabular}{lcc}
\hline Variable & \multicolumn{2}{c}{ Frequency } \\
\cline { 2 - 3 } & $\boldsymbol{n}$ & $\mathbf{\%}$ \\
\hline Partner education & 8 & \\
None & 40 & 4.0 \\
Primary & 123 & 20.0 \\
Secondary & 11 & 61.5 \\
Post-secondary & & 5.5 \\
Partner religion & 160 & \\
Christian & 22 & 80.0 \\
Muslim & 18 & 11.0 \\
Other & & 9.0 \\
Partner occupation & 13 & \\
Unemployed & 88 & 6.5 \\
Paid employees & 85 & 44.0 \\
Self-employed & 14 & 42.5 \\
Other & & 7.0 \\
\hline
\end{tabular}

TABLE 3: Attitudes towards intimate partner violence.

\begin{tabular}{lcc}
\hline Is a man justified to beat a woman for the following & \multicolumn{2}{c}{ Frequency } \\
\cline { 2 - 3 } reasons & $\boldsymbol{n}$ & $\mathbf{0}$ \\
\hline Going out without letting husband know & 25 & 12.5 \\
Yes & 175 & 87.5 \\
No & & \\
Failing to care for the children & 22 & 11.0 \\
Yes & 178 & 89.0 \\
No & & \\
Answering back during an argument & 20 & 10.0 \\
Yes & 180 & 90.0 \\
No & & \\
Refusing sex & 9 & 4.5 \\
Yes & 191 & 95.5 \\
No & & \\
Burning food & 7 & 3.55 \\
Yes & 190 & 96.45 \\
No &
\end{tabular}

\section{Experience of violence}

Half $(50.0 \%)$ of the participants reported to have ever experienced some form of IPV in their present or past relationship. A total of $14 \%$ reported to have ever experienced physical violence whilst pregnant with the current or previous pregnancy. The frequency of violence was considered severe if a person reported to have experienced any form of violence more than five times and moderate if violence occurred less than five times and there were no injuries sustained requiring medical attention. In the past 12 months, $19.0 \%$ of the participants experienced physical violence, $20.0 \%$ experienced sexual violence and $31.5 \%$ experienced emotional or psychological violence. In the past 6 months, $15.6 \%$ experienced physical violence, $16.6 \%$ experienced sexual violence and $26.6 \%$ experienced emotional or psychological violence. In the past three months, $12.6 \%$ experienced physical violence, $16.0 \%$ experienced sexual violence and $21.6 \%$ experienced emotional or psychological violence. Table 4 shows the frequency and severity of experiencing physical, emotional and sexual violence.

Overall, $87(43.7 \%)$ of the participants had experienced physical, emotional or sexual violence in the past 1 year. In
TABLE 4: Frequency of experiencing severity of physical, emotional and sexual violence.

\begin{tabular}{|c|c|c|}
\hline \multirow[t]{2}{*}{ Variable } & \multicolumn{2}{|c|}{ Frequency } \\
\hline & $n$ & $\%$ \\
\hline \multicolumn{3}{|c|}{ Experience of physical abuse past year } \\
\hline None & 161 & 82.14 \\
\hline Moderate & 26 & 13.27 \\
\hline Severe & 9 & 4.59 \\
\hline \multicolumn{3}{|c|}{ Experience of sexual violence past year } \\
\hline None & 164 & 82.00 \\
\hline Moderate & 10 & 5.00 \\
\hline Severe & 26 & 13.00 \\
\hline \multicolumn{3}{|c|}{ Experience of emotional violence past year } \\
\hline None & 135 & 68.53 \\
\hline Moderate & 40 & 20.00 \\
\hline Severe & 22 & 11.00 \\
\hline \multicolumn{3}{|c|}{ Experience of physical violence past 6 months } \\
\hline None & 168 & 84.42 \\
\hline Moderate & 22 & 11.06 \\
\hline Severe & 9 & 4.52 \\
\hline \multicolumn{3}{|c|}{ Experience of sexual violence past 6 months } \\
\hline None & 166 & 83.84 \\
\hline Moderate & 14 & 7.07 \\
\hline Severe & 18 & 9.09 \\
\hline \multicolumn{3}{|c|}{ Experience of emotional violence past 6 months } \\
\hline None & 146 & 73.37 \\
\hline Moderate & 32 & 16.08 \\
\hline Severe & 21 & 10.55 \\
\hline \multicolumn{3}{|c|}{ Experience of physical violence past 3 months } \\
\hline None & 174 & 87.44 \\
\hline Moderate & 15 & 7.54 \\
\hline Severe & 10 & 5.03 \\
\hline \multicolumn{3}{|c|}{ Experience of sexual violence past 3 months } \\
\hline None & 167 & 83.92 \\
\hline Moderate & 15 & 7.54 \\
\hline Severe & 17 & 8.54 \\
\hline \multicolumn{3}{|c|}{ Experience of emotional violence past 3 months } \\
\hline None & 156 & 78.39 \\
\hline Moderate & 23 & 11.56 \\
\hline Severe & 20 & 10.05 \\
\hline
\end{tabular}

the univariate logistic regression analysis, factors that were independently associated $(p<0.05)$ with experience of violence in the past 12 months were pregnancy, duration of relationship, nature of relationship, partner religion, feeling about safety of relationship, willingness to participate in IPV prevention groups and depression.

After adjusting for age and educational level of the participants as possible confounders, the multivariate logistic regression model showed that feelings about safety of the relationship and depression were the only factors that were associated with IPV in the last 12 months $(p=0.001$, Pseudo $R^{2}=0.20$ ). Table 5 shows the results of the multivariate logistic regression analysis.

\section{Discussion}

In our sample of $200 \mathrm{HIV}$-positive women, 50\% reported to have experienced various forms of IPV in the last 12 months. This finding is comparable with findings from previous studies around the globe where the prevalence of IPV ranged 
TABLE 5: Multivariate logistic regression model.

\begin{tabular}{|c|c|c|c|}
\hline Variable & Odds ratio & $95 \% \mathrm{Cl}$ & $p$-value \\
\hline \multicolumn{4}{|l|}{ Age } \\
\hline$\leq 28$ & Ref. & - & - \\
\hline $29>$ & 1.764 & $0.811-3.838$ & 0.152 \\
\hline \multicolumn{4}{|l|}{ Education } \\
\hline Primary or less & Ref. & - & - \\
\hline Secondary and above & 1.167 & $0.562-2.422$ & 0.679 \\
\hline \multicolumn{4}{|l|}{ Pregnant } \\
\hline Yes & Ref. & - & - \\
\hline No & 1.333 & $0.623-2.852$ & 0.459 \\
\hline \multicolumn{4}{|l|}{ Relationship duration } \\
\hline$<1$ year & Ref. & - & - \\
\hline $1-2$ years & 0.245 & $0.056-1.080$ & 0.063 \\
\hline $3-5$ years & 0.7182 & $0.169-3.048$ & 0.654 \\
\hline$>5$ years & 0.491 & $0.130-1.850$ & 0.293 \\
\hline Not applicable & 0.521 & $0.027-10.156$ & 0.667 \\
\hline \multicolumn{4}{|l|}{ Nature of relationship } \\
\hline Married monogamous & Ref. & - & - \\
\hline Married polygamous & 0.918 & $0.056-1.080$ & 0.897 \\
\hline $\begin{array}{l}\text { Steady partner not living } \\
\text { together }\end{array}$ & 0.514 & $0.169-3.048$ & 0.418 \\
\hline Steady partner living together & 0.391 & $0.130-1.850$ & 0.222 \\
\hline Causal relationship & 1.757 & $0.027-10.156$ & 0.750 \\
\hline \multicolumn{4}{|l|}{ Number of sex partners } \\
\hline One & Ref. & - & - \\
\hline Did not disclose & 0.752 & $0.201-2.809$ & 0.672 \\
\hline Three & 0.138 & $0.012-1.614$ & 0.115 \\
\hline \multicolumn{4}{|l|}{ Partner religion } \\
\hline Christian: Catholic & Ref. & - & - \\
\hline Christian: Protestant & 0.721 & $0.314-1.661$ & 0.444 \\
\hline Muslim & 0.819 & $0.237-2.832$ & 0.752 \\
\hline Other & 0.992 & $0.153-6.457$ & 0.994 \\
\hline \multicolumn{4}{|l|}{ Feels safe in relationship } \\
\hline Yes & Ref. & - & - \\
\hline No & 2.985 & $1.334-6.682$ & $0.008 *$ \\
\hline \multicolumn{4}{|l|}{$\begin{array}{l}\text { Opinion about IPV enquires } \\
\text { during ANC visits }\end{array}$} \\
\hline Yes & Ref. & - & - \\
\hline No & 1.842 & $0.292-11.625$ & 0.516 \\
\hline \multicolumn{4}{|l|}{ Willingness to join any group } \\
\hline Yes & Ref. & - & - \\
\hline No & 2.854 & $0.629-12.946$ & 0.174 \\
\hline \multicolumn{4}{|l|}{ Depressed } \\
\hline Yes & Ref. & - & - \\
\hline No & 5.826 & $1.908-17.789$ & $0.002 *$ \\
\hline
\end{tabular}

ANC, antenatal clinic; $\mathrm{Cl}$, confidence interval; IPV, intimate partner violence; Ref., reference. $*, p<0.01$.

from $27.4 \%$ to $55.0 \%, 1,29,30,31,32,33,34,36$ but slightly lower than those obtained amongst antenatal attendees from Nsanje district hospital in Malawi, which reported prevalence of 59.0\%. ${ }^{26}$ In addition, our participants reported high prevalence of sexual $(18 \%)$ than physical IPV (17.86\%), which is a departure from previous studies, which rated physical IPV higher than sexual IPV. ${ }^{1,38,43}$ Although the difference observed here is not statistically significant, a more plausible explanation would be that more women are now becoming aware of their rights and are removing the veil of silence that shrouded the issues of sexual violence within the intimate relationship.

Our study also revealed that the most common form of violence women experienced across the different reporting cut-off points (from 1 year, 6 months and 3 months) was emotional or psychological in nature $(31 \%)$. The higher rates of psychological violence is of major concern considering that at present, it is well-documented that IPV can cause extensive mental health consequences amongst its victims such as symptoms of post-traumatic stress disorder (PTSD) along with other comorbid symptoms such as depression, anxiety, suicidality, substance ${ }^{50}$ abuse and sleep disturbances and can interrupt uptake and adherence to PMTCT services.

When we did univariate logistic regression analysis, we found the factors that were independently associated $(p<0.05)$ with experience of violence in the past 12 months were pregnancy, duration of relationship, nature of relationship, partner religion, feeling about safety of relationship, willingness to join IPV prevention groups and depression. However, woman's education and that of the partner were not independently associated with IPV as was the case with previous studies conducted in other African countries ${ }^{31,38,39,41,42,43}$ including Malawi ${ }^{38,43}$ where higher education was protective against IPV.

Considering the high levels of psychological violence in this study, it was not surprising that after adjusting for age and educational level of the participants as possible confounders, the multivariate logistic regression model showed that feelings about safety of the relationship and depression were the only factors that were associated with IPV in the last 12 months $\left(p=0.01\right.$, Pseudo $\left.R^{2}=0.20\right)$. Women who reported that they don't feel safe in their relationship and those found to be depressed using the SRQ were more likely to have experienced any form of violence in the last 12 months. Our study is not the first to find a consistent relationship between IPV and depression as previous studies from Malawi $\mathrm{i}^{47,48,49}$ and elsewhere ${ }^{50}$ have made similar observations amongst pregnant women, and more so, amongst those experiencing IPV ${ }^{51}$ and are HIV-positive. ${ }^{52,53}$ However, our study's finding on the relationship between safety in a relationship and IPV is in contrast to an earlier study in primary care, which found that many women who reported experiencing violence in their relationship did not report feeling unsafe at home. ${ }^{54}$

The difference between our study and the other studies ${ }^{54}$ is that we recruited women with the triple burden for depression (perinatal, IPV experience and HIV-positive). Unfortunately, tools for screening depression have been validated in the country $47,53,56$ but mental health services for such women are non-existent as perinatal health services in the country are biased towards provision of physical health ${ }^{55,57}$ and routine screening for maternal depression is not done.

In addition, our study's findings underscore the importance of conducting risk assessment for clients reporting any form of violence. A recent study supported the validity of both structured risk assessment tools and victim perceptions as predictors of risk for repeated IPV. ${ }^{46}$ Combining structured risk assessments and victim risk assessments leads to better predictions of repeat violence than when performed separately, suggesting that the two forms of assessment provide unique 
and complementary information. However, these tools have not been tried in our settings and there might be a need for psychometrically testing these to ensure their sensitivity.

\section{Conclusion}

Our research demonstrates that depression and safety issues are major problems that perinatal mothers who are HIV-positive encounter and also points to what can be learned about the changing dynamics in the variables that really matter with regard to our understanding of IPV. However, one limitation of our study is that it was a crosssectional study, as such we cannot confirm the direction of influence between IPV and the associated factors. Nonetheless, the presence of depression and safety concerns amongst our study participants calls for serious prioritisation of psychological interventions and risk assessment in the management of HIV-positive perinatal mothers who report IPV cases. There might be a need to also validate the risk assessment tools and IPV screening tools within these settings to ensure that they are culturally responsive and include a question on safety as a proxy for screening violence in relationships. In addition, the results also suggested that participants who had experienced violence are more likely to express interest to join IPV prevention support groups. Healthcare providers will have to be trained to gain knowledge and skills on how to address IPV situations as they arise in the context of their duty.

\section{Acknowledgements}

The authors would like to acknowledge the invaluable contribution of all who assisted with data collection and review of this article.

\section{Competing interests}

The authors declare that they have no financial or personal relationships that may have inappropriately influenced the writing of this article.

\section{Authors' contributions}

L.C., C.K.-B., U.K., A.S. and G.C.-S. contributed to the design and implementation of the research, to the analysis of the results and to the writing of the manuscript.

\section{Ethical considerations}

Ethical approval to conduct the study was granted by the College of Medicine Research Ethics Committee (reference: p.04/17/2154).

\section{Funding information}

The author received no financial support for the research, authorship and/or publication of this article.

\section{Data availability}

Data sharing is not applicable to this study.

\section{Disclaimer}

The views and opinions expressed in this article are those of the authors and do not necessarily reflect the official policy or position of any affiliated agency of the authors.

\section{References}

1. National Statistical Office (NSO) [Malawi] and ICF. Malawi demographic and health survey 2015-16 [homepage on the Internet], Malawi and Rockville, Maryland: SDO and ICF; 2017.

2. Bancheno WM, Mwanyumba F, Mareverwa J. Outcomes and challenges of scaling up comprehensive PMTCT services in rural Swaziland, Southern Africa. AIDS Care. up comprehensive PMTCT services in rural Swaziland, Southern Africa. A
2010;22(9):1130-1135. https://doi.org/10.1080/09540121003615079

3. Jones SA, Sherman G, Varga CA. Exploring socio-economic conditions and poor follow-up rates of HIV-exposed infants in Johannesburg. South Africa. AIDS Care. 2005;17(4):466-470. https://doi.org/10.1080/09540120412331319723

4. Mepham S, Zondi Z, Mbuyazi A, Mkhwanazi N, Newell ML. Challenges in PMTCT antiretroviral adherence in northern KwaZulu-Natal, South Africa. AIDS Care. 2011;23(6):741-747. https://doi.org/10.1080/09540121.2010.516341

5. Tabana H, Doherty T, Swanevelder S, et al. Knowledge of HIV status prior to a community HIV counseling and testing intervention in a rural district of South Africa: Results of a community based survey. BMC Infect Dis. 2012;12(1):73. https://doi.org/10.1186/1471-2334-12-73

6. Kiarie JN, Farquhar C, Richardson BA. Domestic violence and prevention of mother-to-child transmission of HIV-1. AIDS. 2006;20(13):1763-1769. https://doi. org/10.1097/01.aids.0000242823.51754.0c

7. Kaye DK. Gender inequality and domestic violence: Implications for human immunodeficiency virus (HIV) prevention. Afr Health Sci. 2004;4(1):67-70.

8. Hatcher AM, Woollett N, Pallitto CC, et al. Bidirectional links between HIV and intimate partner violence in pregnancy: Implications for prevention of mother-tointimate partner violence in pregnancy: Implications for prevention of mother-to-
child transmission. J Int AIDS Soc. 2014;17(1):19233. https://doi.org/10.7448/ child transmission.
IAS.17.1.19233

9. Fonck K, Els L, Kidula N, Ndinya-Achola J, Temmerman M. Increased risk of HIV in women experiencing physical partner violence in Nairobi, Kenya. AIDS Behav. 2005;9(3):335-339. https://doi.org/10.1007/s10461-005-9007-0

10. Donahue MC, Dube Q, Dow A, Umar E, Van Rie A. 'They have already thrown away their chicken': Barriers affecting participation by HIV-infected women in care and treatment programs for their infants in Blantyre, Malawi. AIDS Care. 2012;24(10):1233-1239. https://doi.org/10.1080/09540121.2012.656570

11. Parrott FR, Mwafulirwa C, Ngwira B, et al. Combining qualitative and quantitative evidence to determine factors leading to late presentation for antiretroviral therapy in Malawi. PLoS One. 2011:6(11):e27917. https://doi.org/10.1371/ journal.pone.00279171124

12. Chinkonde JR, Sundby J, Martinson F. The prevention of mother-to-child HIV transmission programme in Lilongwe, Malawi: Why do so many women drop out. Reprod Health Matters. 2009;17(33):143-151. https://doi.org/10.1016/S09688080(09)33440-0

13. Hardon A, Vernooij E, Bongololo-Mbera G, et al. Women's views on consent, counseling and confidentiality in PMTCT: A mixed-methods study in four African countries. BMC Public Health. 2012;12(1):26. https://doi.org/10.1186/1471 2458-12-26

14. Bwirire LD, Fitzgerald $M$, Zachariah $R$, et al. Reasons for loss to follow-up among mothers registered in a prevention-of-mother-to-child transmission program in rural Malawi. Trans R Soc Trop Med Hyg. 2008;102(12):1195-1200. https://doi. org/10.1016/j.trstmh.2008.04.002

15. WHO. Global HIV/AIDS response - Epidemic update and health sector progress towards universal access - Progress report summary 2011. Genva: World Health Organization; 2012.

16. Shapiro RL, Hughes MD, Ogwu A, et al. Antiretroviral regimens in pregnancy and breast-feeding in Botswana. N Engl J Med. 2010;362(1):2282-2294. https://doi. org/10.1056/NEJMoa0907736

17. Lehman DA, John-Stewart GC, Overbaugh J. Antiretroviral strategies to prevent mother-to-child transmission of HIV: Striking a balance between efficacy, feasibility, and resistance. PLoS Med. 2009;6(10):e1000169. https://doi. org/10.1371/journal.pmed.1000169

18. Clouse KPA, Shearer K, Maskew M, et al. Loss to follow-up before and after delivery amongwomen testing HIV positive during pregnancy in Johannesburg, South Africa. Trop Med Int Health. 2013;18(4):451-460. https://doi.org/10.1111/ tmi.12072

19. Goga AE, Doherty $T$, Jackson DJ, et al. Infant feeding practices at routine PMTCT sites, South Africa: Results of a prospective observational study amongst HIV exposed and unexposed infants - Birth to 9 months. Int Breastfeed J. 2012;7(4):4. https://doi.org/10.1186/1746-4358-7-4

20. Laher F, Cescon A, Lazarus E, et al. Conversations with mothers: Exploring reasons for prevention of mother-to-child transmission (PMTCT) failures in the era of programmatic scale-up in Soweto, South Africa. AIDS Behav. 2012:16(1):91-98. https://doi.org/10.1007/s10461-010-9875-9

21. Manzi M, Zachariah R, Teck R, et al. High acceptability of voluntary counselling and HIV-testing but unacceptable loss to follow up in a prevention of mother-tochild HIV transmission programme in rural Malawi: Scaling-up requires a different way of acting. Trop Med Int Health. 2005;10(12):1242-1250. https://doi. org/10.1111/j.1365-3156.2005.01526.x 
22. Tenthani $\mathrm{L}$, Haas AD, Tweya $\mathrm{H}$, et al. Retention in care under universal antiretroviral therapy for HIV-infected pregnant and breastfeeding women ('Option B+') in Malawi. AIDS. 2014;28(4):589-598. https://doi.org/10.1097/QAD.0000000000000143

23. Saur M, Semu L, Ndau S. Nkhanza listening to peoples voices: $A$ base line study of gender based violence 'nkhanza' in three districts of Malawi. Zomba: GTZ, Ministry of Gender and Community Services; 2003.

24. Becker S, Mlay R, Schwandt HM, Lyamuya E. Comparing couples' and individual voluntary counseling and testing for HIV at antenatal clinics in Tanzania: A randomized trial. AIDS Behav. 2010;14(3):558-566. https://doi.org/10.1007/ s10461-009-9607-1

25. National Statistical Office (NSO) and ICF. Marco. Malawi demographic and health survey 2010. Zambia, Malawi, and Calverton, Maryland: NSO and ICF Macro; 2011.

26. Chasweka R, Chimwaza A, Maluwa A, Odland JO. Magnitude of domestic violence against Pregnant women in Malawi. J Res Nurs Midwifery. 2012;1(2):17-22.

27. Bisika T. Do social and cultural factors perpetuate gender based violence in Malawi? Gender Behav. 2008;6(2):1884-1896. https://doi.org/10.4314/gab. v6i2.23426

28. Pelser E, Gondwe L, Mayamba C, Mhango T, Phiri W, Burton P. Intimate partner violence: Results from a national gender-based violence study in Malawi. Pretoria: Crime and Justice Statistical Division National Statistical Office, 2005; p. 1-34.

29. Chinangwa S. Community mobilisation on the twin pandemic of gender based violence and HIV/AIDS: An advocacy for social justice project Gender based violence survey in Malawi. Lilongwe: Malawi Human Rights Resource Centre (MHRRC); 2009.

30. Machtinger EL, Wilson TC, Haberer JE, Weiss DS. Psychological trauma and PTSD in HIV-positive women: A meta-analysis. AIDS Behav. 2012;16(8):2091-2100. https://doi.org/10.1007/s10461-011-0127-4

31. Makayoto LA, Omolo J, Kamweya AM, Harder VS, Mutai J. Prevalence and associated factors of intimate partner violence among pregnant women attending
Kisumu District Hospital, Kenya. Matern Child Health J. 2013;17(3):441-447. Kisumu District Hospital, Kenya. Matern Chic
https://doi.org/10.1007/s10995-012-1015-x

32. Shamu S, Zarowsky C, Shefer T, Temmerman M, Abrahams N. Intimate partner violence after disclosure of HIV test results among pregnant women in Harare, Zimbabwe. PLoS One. 2014;9(10):e109447. https://doi.org/10.1371/journal. pone.0109447

33. Siemieniuk RAC, Krentz HB, Miller P, Woodman K, Ko K, Gill MJ. The clinical implications of high rates of intimate partner violence against HIV-positive women. JAIDS. 2013;64(1):32-38. https://doi.org/10.1097/qai.0b013e31829bb007

34. Rees $\mathrm{S}$, Silove $\mathrm{D}$, Chey $\mathrm{T}$, et al. Lifetime prevalence of gender-based violence in women and the relationship with mental disorders and psychosocial function. JAMA. 2011;306(5):513-521. https://doi.org/10.1001/jama.2011.1098

35. Decker MR, Crago A-L, Chu SKH, et al. Human rights violations against sex workers: Burden and effect on HIV. Lancet. 2015;385(9963):186-199. https://doi. org/10.1016/S0140-6736(14)60800-X

36. Decker MR, Latimore AD, Yasutake $S$, et al. Gender-based violence against adolescent and young adult women in low- and middle-income countries. J Adoles Health. 2015;56(2):188-196. https://doi.org/10.1016/j.jadohealth.2014.09.003

37. Gazmararian JA, Petersen R, Spitz AM, Goodwin MM, Saltzman LE, Marks JS. Violence and reproductive health: Current knowledge and future research directions. Matern Child Health J. 2000;4(2):79-84. https://doi.org/10.1023/a:1009514119423

38. Conroy AA. Gender, power, and intimate partner violence: A study on couples from rural Malawi. J Interpers Violence. 2014;29(5):866-888. https://doi. org/10.1177/0886260513505907

39. Gass JD, Stein DJ, Williams DR, Seedat S. Gender differences in risk fo intimate partner violence among South African adults. J Interpers Violence. 2011;26(14):2764-2789. https://doi.org/10.1177/0886260510390960

40. Choi SY, Ting KF. Wife beating in South Africa: An imbalance theory of resources and power. J Interpers Violence. 2008;23(6):834-852. https://doi.org/10.1177/
0886260507313951
41. Were E, Curran K, Delany-Moretlwe S, et al. A prospective study of frequency and correlates of intimate partner violence among African heterosexual HIV serodiscordant couples. AIDS. 2011;25(16):2009-2018. https://doi.org/10.1097/ QAD.0b013e32834b005d

42. Karamagi C, Tumwine J, Tylleskar T, Heggenhougen K. Intimate partner violence against women in eastern Uganda: Implications for HIV prevention. BMC Public Health. 2006;6(1):284. https://doi.org/10.1186/1471-2458-6-284

43. Bazargan-Hejazi S, Medeiros S, Mohammadi R, Lin J, Dalal K. Patterns of intimate partner violence: A study of female victims in Malawi. J Inj Violence Res. 2013;5(1):38-50. https://doi.org/10.5249/jivr.v5i1.139

44. Abramsky T, Watts C, Garcia-Moreno C, et al. What factors are associated with recent intimate partner violence? findings from the WHO multi-country study on women's health and domestic violence. BMC Public Health. 2011;11(1):109. https://doi.org/10.1186/1471-2458-11-109

45. Lemeshow S, Hosmer DW, Klar J, Lwanga SK. Adequacy of sample size in health studies. Chichester: Wiley; 1990.

46. Arkins B, Begley C, Higgins A. Measures for screening for intimate partner violence: A systematic review. J Psychiatr Ment Health Nurs. 2016;23(3-4): 217-235. https://doi.org/10.1111/jpm.12289

47. Antoniou E, loannidi-Kapolou E, Daglas M, et al. (2010). Abuse assessment screen (AAS) questionnaire: The Greek validation. Clin Exp Obstet Gynecol. 2010;37(4):313-316.

48. Escribà-Agüir V, Ruiz-Pérez I, Artazcoz L, Martín-Baena D, Royo-Marqués $M$, Vanaclocha-Espí M. Validity and reliability of the Spanish version of the 'Abuse Assessment Screen' among pregnant women. Public Health Nurs. 2016:33(3): 264-272. https://doi.org/10.1111/phn.12232

49. Stewart RC, Umar E, Tomenson B, Creed F. Validation of screening tools for antenatal depression in Malawi - A comparison of the Edinburgh Postnatal Depression Scale and Self Reporting Questionnaire, I Affect Disord. 2013;150(3):1041-1047. https://doi.org/10.1016/j.jad.2013.05.036

50. Stewart RC, Umar E, Tomenson B, Creed F. A cross-sectional study of antenatal depression and associated factors in Malawi. Arch Womens Ment Health. 2014;17(2):145-154.

51. Chorwe-Sungani G, Chipps J. A cross-sectional study of depression among women attending antenatal clinics in Blantyre district, Malawi. J Afr Psychiatr. 2018;24(1):1181. https://doi.org/10.4102/sajpsychiatry.v24i0.1181

52. Fisher J, Cabral de Mello M, Patel V, et al. Prevalence and determinants of common perinatal mental disorders in women in low- and lower-middle-income countries: A systematic review. Bul World Health Organ. 2012;90(2):139-149H. https://doi.org/10.2471/BLT.11.091850

53. Stewart RC, Umar E, Gleadow-Ware S, Creed F, Bristow K. Perinatal distress and depression in Malawi: An exploratory qualitative study of stressors, supports and symptoms. Arch Womens Ment Health. 2015;18(2):177-185. https://doi. org/10.1007/s00737-014-0431-x

54. Peralta RL, Fleming MF. Screening for intimate partner violence in a primary care setting: The validity of 'feeling safe at home' and prevalence results. J Am Board Fam Pract. 2003;16(6):525-532. https://doi.org/10.3122/jabfm.16.6.525

55. Harrington $\mathrm{BJ}$, Pence BW, John $\mathrm{M}$, et al. Prevalence and factors associated with antenatal depressive symptoms among women enrolled in Option B antenatal HIV care in Malawi: A cross-sectional analysis. J Ment Health 2019;28(2):198-205. https://doi.org/10.1080/09638237.2018.1487542

56. Chorwe-Sungania G, Chipps J. Validity and utility of instruments for screening of depression in women attending antenatal clinics in Blantyre district in Malawi. S Afr Fam Pract. 2018:60(4):114-120. https://doi.org/10.1080/20786190.2018.143 2136

57. Chepuka L, Taegtmeyer M, Chorwe-Sungani G, Mambulasa J, Chirwa E, Tolhurst R. Perceptions of the mental health impact of intimate partner violence and health service responses in Malawi. Glob Health Action. 2014;7(1):24816. https://doi. org/10.3402/gha.v7.24816 